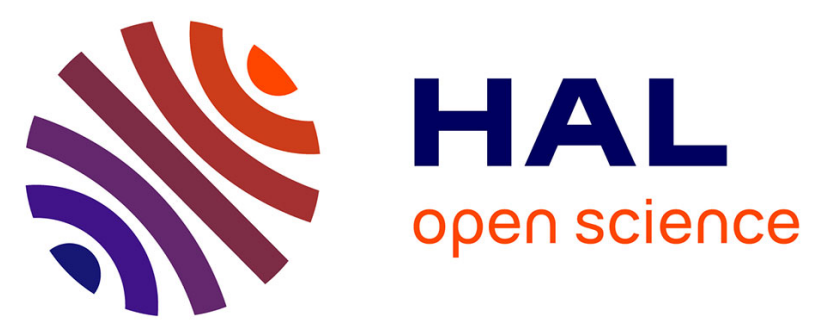

\title{
Effect of electropolymerisation conditions on the permeability of polyphenol films deposited on a vitreous carbon electrode
}

Noureddine Belhadj Tahar, André Savall

\section{- To cite this version:}

Noureddine Belhadj Tahar, André Savall. Effect of electropolymerisation conditions on the permeability of polyphenol films deposited on a vitreous carbon electrode. Electrochimica Acta, 2012, vol. 82, pp. 427-433. 10.1016/j.electacta.2012.06.080 . hal-00878691

\section{HAL Id: hal-00878691 \\ https://hal.science/hal-00878691}

Submitted on 30 Oct 2013

HAL is a multi-disciplinary open access archive for the deposit and dissemination of scientific research documents, whether they are published or not. The documents may come from teaching and research institutions in France or abroad, or from public or private research centers.
L'archive ouverte pluridisciplinaire HAL, est destinée au dépôt et à la diffusion de documents scientifiques de niveau recherche, publiés ou non, émanant des établissements d'enseignement et de recherche français ou étrangers, des laboratoires publics ou privés. 


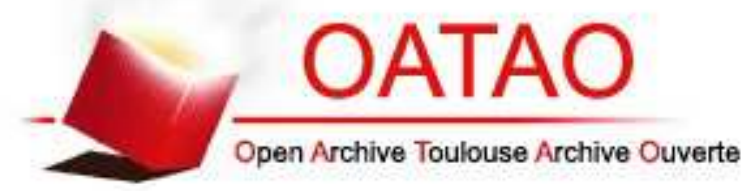

\section{Open Archive TOULOUSE Archive Ouverte (OATAO)}

OATAO is an open access repository that collects the work of Toulouse researchers and makes it freely available over the web where possible.

This is an author-deposited version published in : http://oatao.univ-toulouse.fr/ Eprints ID : 10005

To link to this article : doi:10.1016/j.electacta.2012.06.080

URL : http://dx.doi.org/10.1016/j.electacta.2012.06.080

To cite this version : Belhadj Tahar, Noureddine and Savall, André

Effect of electropolymerisation conditions on the permeability of polyphenol films deposited on a vitreous carbon electrode. (2012)

Electrochimica Acta, vol. 82 . pp. 427-433. ISSN 0013-4686

Any correspondance concerning this service should be sent to the repository administrator: staff-oatao@ listes-diff.inp-toulouse.fr 


\title{
Effect of electropolymerisation conditions on the permeability of polyphenol films deposited on a vitreous carbon electrode
}

\author{
Noureddine Belhadj Tahar ${ }^{\mathrm{a}}$, André Savall ${ }^{\mathrm{b}, *}$ \\ a Institut Supérieur des Sciences Appliquées et Technologie de Mahdia, Université de Monastir, Tunisia

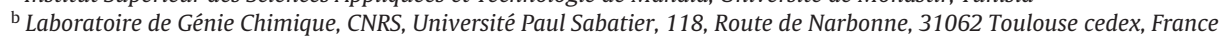

\begin{abstract}
A B S T R A C T
Polymeric films were prepared from alkaline $(\mathrm{NaOH})$ phenol aqueous solutions on a vitreous carbon (VC) electrode by potentiostatic or galvanostatic electro-oxidation. Permeation through such films was studied by rotating-disk electrode using the ferricyanide redox couple, and by cyclic voltammetry using phenate ions. The influence of the electropolymerisation controllable parameters such as $\mathrm{NaOH}$ and phenol concentrations, potential or current applied, electrosynthesis time, temperature and hydrodynamic conditions (electrode rotation + solution magnetic stirring) on the permeability of these polymeric films was examined. Conditions for the removal of phenol by electropolymerisation are discussed on the basis of the permeability of polyphenol films obtained by electrosynthesis. Permeable films were formed for a concentration of free hydroxyl anion larger of $0.1 \mathrm{M}$. An increase of the temperature to $85^{\circ} \mathrm{C}$ favours the formation of highly permeable films, thus avoiding electrode fouling.
\end{abstract}

Rotating-disk electrode

Phenol electropolymerisation

Vitreous carbon

Permeability

Wastewater treatment

\section{Introduction}

In recent years there has been an increasing interest in the development of electrochemical polymerisation for the removal of phenols from aqueous solutions. The main advantage in proceeding by electropolymerisation is the low consumption of the electric charge compared with electrochemical mineralisation [1]. In this way, the removal of phenols from aqueous solutions by electrochemical polymerisation was conducted on granular activated carbon [2], carbon fibre [3], $\mathrm{Ta} / \beta-\mathrm{PbO}_{2}[1,4]$ and polyaniline/glassy carbon electrodes [5]. Nevertheless, electropolymerisation of phenolic compounds leads to the deposition of a non-conductive film that blocks the electrode activity and prevents further removal of phenol [6-11]. Many works have shown that diffusion of electroactive species through polymeric films depends on the electropolymerisation conditions such as the monomer concentration [12], the nature of the solvent used [13], the $\mathrm{pH}$ and background electrolyte [14], the degree of cross-linking of the polymer chains [15], the nature of the electrode [16], the electrodeposition modes (cyclic voltammetry and potentiostatic or galvanostatic electrolysis) $[12,17]$, the applied potential $[14,18]$ or current [19] and the electropolymerisation time (film thickness) [12].

The aim of our previous works $[1,4,20,21]$ was to find the operating conditions that allow electropolymerisation to proceed as long

\footnotetext{
* Corresponding author. Tel.: +33 5 61556110; fax: +33 561556139.

E-mail addresses: nour.belhadj@fsm.rnu.tn (N. Belhadj Tahar), savall@chimie.ups-tlse.fr (A. Savall).
}

as a current is supplied to the electrode; thus, the polymeric film inevitably deposited on the electrode surface must have the highest permeability for phenol molecules. The main operating conditions were described in Ref. [1]. The electrochemical response of phenate ion on bare VC and polyphenol film-coated VC was studied in $1 \mathrm{M} \mathrm{NaOH}$ aqueous solutions [20]. However using such high concentration of $\mathrm{NaOH}$ in the precursor phenol solution penalizes any eventual treatment based on the removal of phenols by electropolymerisation. The aim of this work was to measure by using a rotating-disk electrode the permeability for ferricyanide anion of polyphenol films deposited in alkaline medium on VC under various electropolymerisation conditions. In particular we are looking for the minimal concentration of $\mathrm{NaOH}$ which allows the continuous forming of a film of sufficient permeability not to block the electropolymerisation. The relative permeability for phenate anion was also evaluated by monitoring changes in cyclic voltammograms of phenol solution recorded on polyphenol film-coated VC as compared to bare VC. In order to optimise the concentration of $\mathrm{NaOH}$ in the precursor phenol solution particular attention was paid to its effect on the permeability of the polyphenol film.

\section{Experimental}

\subsection{General}

Cyclic and rotating-disk voltammetry and chronoamperometry measurements were performed using a computer controlled Eco Chemie Autolab Model 30 (Utrecht, The Netherlands). The conventional three-electrode cell system consisted of bare VC or 
polyphenol film-covered VC (disk of $3 \mathrm{~mm}$ diameter, Metrohm) working electrode, a platinum spiral counter electrode and an $\mathrm{Hg} / \mathrm{Hg}_{2} \mathrm{Cl}_{2} / \mathrm{Cl}^{-}$(saturated) reference electrode connected to the electrolytic solution by a long Luggin capillary placed near the working electrode and filled with $0.1 \mathrm{M} \mathrm{Na}_{2} \mathrm{SO}_{4}$. All the potentials are reported versus the above specified reference electrode. Before each experiment, the working electrode was polished to a mirror with $1 \mu \mathrm{m}$ alumina slurries on polishing sheet (3 M 262X IMPERIAL Lapping Film) and subsequently washed with distilled water.

\subsection{Preparation of polyphenol film-coated vitreous carbon} electrode

Polyphenol films were prepared by oxidative electropolymerisation performed either galvanostatically or potentiostatically onto the disk of $\mathrm{VC}$ electrode surface from phenol aqueous solutions containing $0.1 \mathrm{M} \mathrm{Na}_{2} \mathrm{SO}_{4}$ and $\mathrm{NaOH}$ at various concentrations. Electropolymerisation was performed on a fixed electrode and without magnetic stirring unless otherwise instructed. The polyphenol filmcoated electrodes were copiously rinsed with distilled water and used immediately in permeation experiments.

\subsection{Polyphenol film permeability measurement}

The permeability $P_{\text {ferr. }}^{\text {film }}$ of the polyphenol film for ferricyanide anion was measured with a rotating-disk electrode (RDE) in $\mathrm{pH}$ 7 phosphate $(0.1 \mathrm{M})$ buffer solution containing $0.01 \mathrm{M}$ potassium ferricyanide at $25^{\circ} \mathrm{C}$. The limiting current $I_{\mathrm{L}}$ of the electrochemical reduction of ferricyanide anion on the polyphenol film-covered RDE can be described by the following equation [22]:

$I_{\mathrm{L}}^{-1}=\left(n F A C_{\mathrm{S}} P_{\text {ferr. }}^{\text {film }}\right)^{-1}+\left(0.62 n F A C_{\mathrm{s}} D_{\mathrm{s}}^{2 / 3} v^{-1 / 6}\right)^{-1} \omega^{-1 / 2}$

where $A$ is the electrode area $\left(\mathrm{cm}^{2}\right), C_{\mathrm{s}}$ is the concentration of ferricyanide anion in the solution $\left(\mathrm{mol} \mathrm{cm}^{-3}\right), D_{\mathrm{s}}$ is the ferricyanide diffusion coefficient in the solution $\left(\mathrm{cm}^{2} \mathrm{~s}^{-1}\right), v$ is the kinematic viscosity of the solution $\left(\mathrm{cm}^{2} \mathrm{~s}^{-1}\right), \omega$ is the angular rotation rate of the electrode rotation ( $\mathrm{rad} \mathrm{s}^{-1}$ ) and $n(=1)$ and $F$ have their usual meanings.

The permeability of the polyphenol film for ferricyanide anion $P_{\text {ferr. }}^{\text {film }}$ was obtained from the intercepts of $I_{\mathrm{L}}^{-1}$ plots versus $\omega^{-1 / 2}$ at $\omega^{-1 / 2}=0$. The solution permeability for ferricyanide $P_{\text {ferr. }}^{\text {sol. }}$ was obtained from the slopes of plots $I_{\mathrm{d}}$ versus $\omega^{1 / 2}$ where $I_{\mathrm{d}}$ is the limiting current at the bare VC electrode as described by Levich [22]:

$I_{\mathrm{d}}=0.62 n F A C_{\mathrm{s}} D_{\mathrm{s}}^{2 / 3} v^{-1 / 6} \omega^{1 / 2}=n F A C_{\mathrm{s}} P_{\text {ferr. }}^{\text {sol. }}$

The relative permeability of the polyphenol film for phenate anion $P_{\mathrm{Ph} \text {. }}^{\text {film }}$ was assessed by subjecting the polyphenol film-coated electrode to cycling in the same solution used for the film preparation. The relative permeability for phenate anion $P_{\mathrm{Ph} .}^{\text {film }}$, expressed as a percentage, is defined as the ratio of the oxidation peak current intensity during the 1 st scan at the polyphenol film-coated electrode $I_{\text {film }}$ over that at the bare electrode $I_{\text {bare }}[23,24]$ :

$P_{\mathrm{Ph} .}^{\text {film }}=\frac{I_{\text {film }}}{I_{\text {bare }}} \times 100$

In practice, the permeability of the film of polyphenol for ferricyanide anions was calculated from voltammograms recorded at $25^{\circ} \mathrm{C}$ on bare glassy carbon disk (freshly polished) and on this disk covered with the film even when the film was prepared at $85^{\circ} \mathrm{C}$. However, the permeability of the film of polyphenol for phenate anions was calculated from voltammograms recorded on bare VC and on polyphenol film-coated VC in the same solution and at the same temperature used for the preparation of the film.

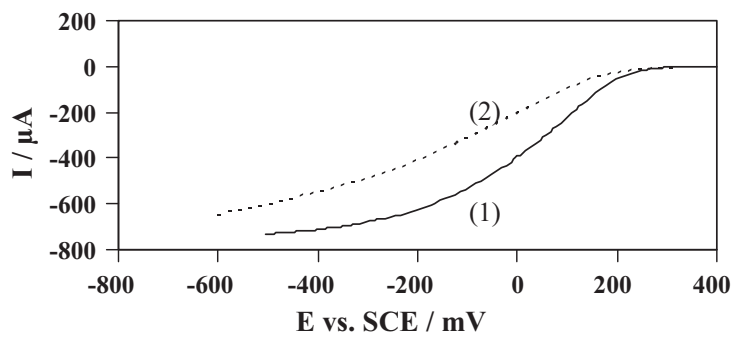

Fig. 1. Voltammograms on a VC rotated disk of $0.01 \mathrm{M}$ potassium ferricyanide in pH 7 sodium phosphate $(0.1 \mathrm{M})$ buffer solution at $25^{\circ} \mathrm{C}$. Scan rate: $10 \mathrm{mV} \mathrm{s}^{-1}$ and $\omega=5000 \mathrm{rpm}$. (1) Bare VC; (2) polyphenol film electrosynthesized on VC rotatingdisk electrode $(\omega=1000 \mathrm{rpm})$ by anodic polarisation at $1800 \mathrm{mV}$ during $60 \mathrm{~min}$ in a magnetically stirred $0.01 \mathrm{M}$ phenol solution containing $0.1 \mathrm{M} \mathrm{NaOH}$ and $0.1 \mathrm{M}$ $\mathrm{Na}_{2} \mathrm{SO}_{4}$ at $85^{\circ} \mathrm{C}$.

\section{Results and discussion}

\subsection{General behaviour of the bare vitreous carbon and the polyphenol film}

Fig. 1 shows typical rotating-disk voltammograms for the reduction of $0.01 \mathrm{M}$ potassium ferricyanide solution at bare and polyphenol film-coated VC electrodes. The film did not affect the starting ferricyanide reduction potential but the current was strongly attenuated.

\subsection{Polyphenol films prepared by potentiostatic oxidation}

Polyphenol films were prepared by potentiostatic oxidation in order to highlight the influence on their permeability of oxygen evolution when it occurs simultaneously with electropolymerisation.

\subsubsection{Influence of temperature}

Values of film permeability were determined by plotting $I_{\mathrm{L}}^{-1}$ vs. $\omega^{-0.5}$ and extrapolating to very high rotation rate at $\omega^{-0.5}=0$, where mass transport is totally film limited. Fig. 2 represents plots of $I_{\mathrm{L}}^{-1}$ vs. $\omega^{-0.5}$ for bare and polymer modified VC electrodes. Table 1 shows
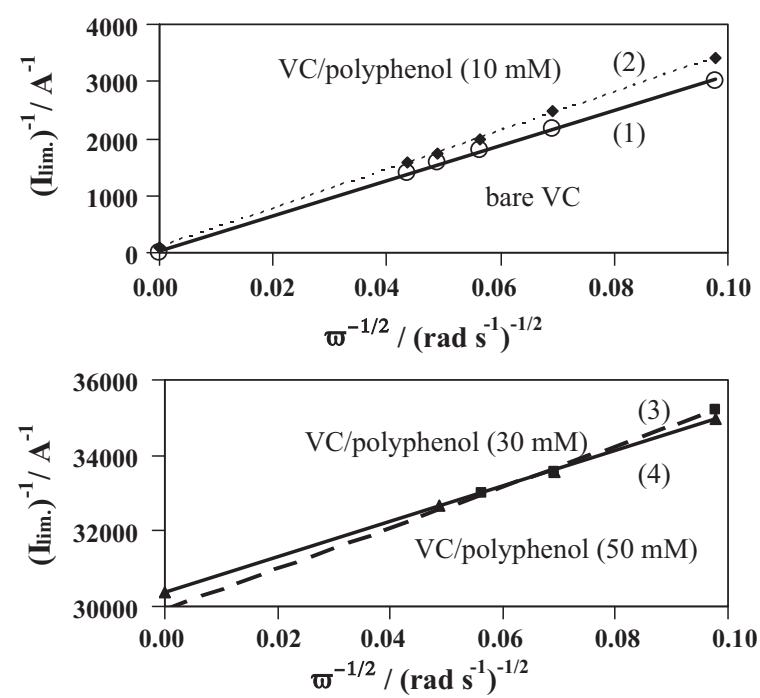

Fig. 2. Reciprocal Levich plots of limiting reduction currents for permeation of ferricyanide anion through films of polyphenol on a VC rotated disk. Scan rate: $10 \mathrm{mV} \mathrm{s}^{-1}$. Polyphenol films were prepared at $85^{\circ} \mathrm{C}$ on a rotating-disk electrode $(\omega=1000 \mathrm{rpm})$ by anodic polarisation at $1800 \mathrm{mV}$ during $30 \mathrm{~min}$ in a magnetically stirred $0.1 \mathrm{M}$ $\mathrm{NaOH}$ and $0.1 \mathrm{M} \mathrm{Na}_{2} \mathrm{SO}_{4}$ aqueous solution with phenol concentrations: $0 \mathrm{M}$ curve (1) (bare VC); $0.01 \mathrm{M}$ curve (2); $0.03 \mathrm{M}$ curve (3) and $0.05 \mathrm{M}$ curve (4). 
Table 1

Relationships between temperature and the permeability for ferricyanide anion of the polyphenol film $P_{\text {ferr }}^{\text {film }}$ electrosynthesized on vitreous carbon electrode during $30 \mathrm{~min}$ at various applied potentials $E$ from $0.01 \mathrm{M}$ phenol aqueous solution containing $1 \mathrm{M} \mathrm{NaOH}$ and $0.1 \mathrm{M} \mathrm{Na}_{2} \mathrm{SO}_{4}$.

\begin{tabular}{lrrrrrr}
\hline$T /{ }^{\circ} \mathrm{C}$ & 25 & \multicolumn{7}{c}{85} \\
\hline$E$ vs. SCE $/ \mathrm{mV}$ & 500 & 900 & 1200 & 500 & 600 & 700 \\
$P_{\text {ferr. }}^{\text {film }} \times 10^{4} / \mathrm{Cm} \mathrm{s}^{-1}$ & 0 & 5 & 221 & 0 & 1961 & 3349 \\
\hline
\end{tabular}

the relationships between the temperature and the permeability of the polyphenol films electrosynthesized on VC during $30 \mathrm{~min}$ at various applied potentials from $0.01 \mathrm{M}$ phenol aqueous solution containing $1 \mathrm{M} \mathrm{NaOH}$ and $0.1 \mathrm{M} \mathrm{Na}_{2} \mathrm{SO}_{4}$. Polyphenol films prepared at potentials less than $500 \mathrm{mV}$ were not at all permeable at both 25 and $85^{\circ} \mathrm{C}$. Above $500 \mathrm{mV}$, the permeability increased substantially at $85^{\circ} \mathrm{C}$ while polyphenol films remained almost impermeable until $900 \mathrm{mV}$ at $25^{\circ} \mathrm{C}$.

The raising of permeability with temperature and applied potential (Table 1) may result from an increase in the polyphenol film growth rate; the diameter and density of the pores in the film are expected to strongly increase with the film growth rate. On the contrary, a film grown slowly is more compact and dense with less and narrower pores [15]. In summary, the larger permeability values were obtained at high temperature, which allows the use of lower potentials.

\subsubsection{Influence of $\mathrm{NaOH}$ concentration}

Fig. 3 shows cyclic voltammograms recorded on bare VC electrode at $85^{\circ} \mathrm{C}$ in $0.01 \mathrm{M}$ phenol aqueous solution containing $0.1 \mathrm{M}$ $\mathrm{Na}_{2} \mathrm{SO}_{4}$ and $\mathrm{NaOH}$ at different concentrations. Decreasing the concentration of $\mathrm{NaOH}$ from 1 to $0.01 \mathrm{M}$ had no effect on the peak potential but noticeably diminished the peak current of phenol oxidation indicating that the electrode passivation was more and more pronounced. Note that for $0.01 \mathrm{M} \mathrm{NaOH}$ the response of phenol (practically present as phenate) is expressed as a wave (curve $3)$.

Table 2 shows the relationships between the permeability for ferricyanide anion and the concentration of $\mathrm{NaOH}$ used during the polyphenol film preparation at various applied potentials. For $\mathrm{NaOH}$ concentration of $1 \mathrm{M}$, polyphenol films prepared at potentials below $500 \mathrm{mV}$ are not at all permeable while the ones prepared at potential higher than $600 \mathrm{mV}$ were highly permeable. In these conditions, comparison between values of $P_{\text {film }}^{\text {filr }}$ (Table 2) and $P_{\text {ferr. }}^{\text {sol. }}$ (Fig. 4) shows that phenol oxidation rate was limited by the low membrane permeability of polyphenol films prepared at potentials lower than $500 \mathrm{mV}$. On the contrary, the oxidation rate was limited by the solution for films prepared at potentials higher than $600 \mathrm{mV}$. Table 2 shows that polyphenol films with high permeability to ferricyanide anion were prepared at increasing potentials as the $\mathrm{NaOH}$ concentration decreased from 1 to $0.01 \mathrm{M}$. On the other hand, very low permeability values were observed even at high applied potentials for $\mathrm{NaOH}$ concentrations less than $0.1 \mathrm{M}$. These results are in

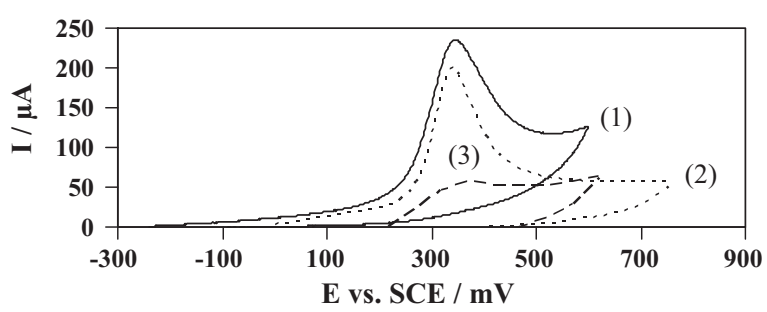

Fig. 3. Effect of sodium hydroxide concentration on cyclic voltammograms (1st cycles). recorded on bare VC electrode in $0.01 \mathrm{M}$ phenol aqueous solution containing $0.1 \mathrm{M} \mathrm{Na}_{2} \mathrm{SO}_{4}$ and $\mathrm{NaOH}$ at a concentration of $1 \mathrm{M}$ (curve 1 ), $0.1 \mathrm{M}$ (curve 2) and $0.01 \mathrm{M}$ (curve 3). Scan rate: $100 \mathrm{mV} \mathrm{s}^{-1}$ and $T=85^{\circ} \mathrm{C}$.

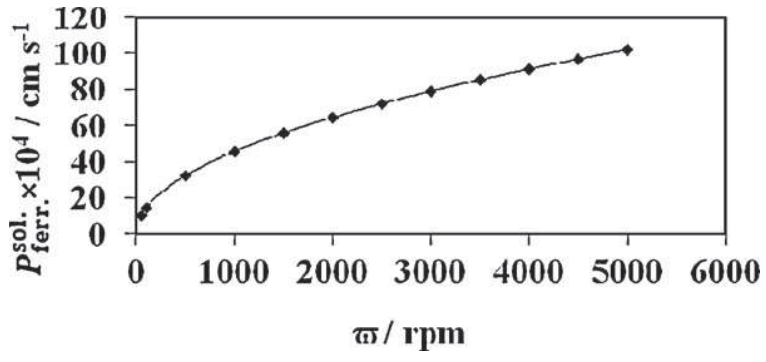

Fig. 4. Variation of the solution permeability for ferricyanide anion as a function of the electrode rotation rate.

agreement with cyclic voltammograms presented in Fig. 3 if we consider that the peak current of phenol oxidation decreased as the permeability of the polyphenol film diminished.

Cyclic voltammograms presented in Fig. 5 show that no phenol oxidation peak was observed for $\mathrm{NaOH}$ concentrations less than $0.1 \mathrm{M}$ (curves 1 and 2) indicating that under these conditions the polyphenol films were impermeable to phenate anion. The relative permeability $P_{\mathrm{Ph}}^{\text {film }}$ for phenate anion of the polymer film prepared in $0.1 \mathrm{M} \mathrm{NaOH}$ was evaluated, according to Eq. (3), from curve 2 in Fig. 3 and curve 3 in Fig. 5. $P_{\mathrm{Ph}}^{\text {film }}$ is equal to 184\%; this value, higher than $100 \%$, suggests that the film permeability for phenate anion is governed by the preferential partitioning of the probe into the polyphenol film due to stronger interactions (electrostatic, hydrophobic, etc.) in the film than in the solution [24].

Phenol is a weak acid ( $\left.\mathrm{p} K_{\mathrm{a}}=9.9\right)$ and at an initial concentration of $0.01 \mathrm{M}$ its reaction with $\mathrm{NaOH}$ initially at $1 \mathrm{M}, 0.1 \mathrm{M}, 0.05 \mathrm{M}$ or $0.01 \mathrm{M}$ leads to equilibrium concentrations of free $\mathrm{OH}^{-}$respectively equal to $0.99 \mathrm{M}, 0.09 \mathrm{M}, 0.04 \mathrm{M}$ and $0.00 \mathrm{M}$. Consequently, at relatively high $\mathrm{NaOH}$ initial concentration $(1 \mathrm{M}$ and $0.1 \mathrm{M}$ ) there is enough free $\mathrm{OH}^{-}$to instantaneously neutralize the acidity arising at the electrode surface from water discharge occurring in parallel with polyphenol electrosynthesis. On the other hand, with low $\mathrm{NaOH}$ concentrations $(0.05$ and $0.01 \mathrm{M})$ the free $\mathrm{OH}^{-}$concentration is too weak to neutralize the totality of protons produced at the surface of the anode when the applied potential increases. Furthermore, the low values of permeability observed with the lower $\mathrm{NaOH}$ concentrations ( 0.05 and $0.01 \mathrm{M}$ ), even for experiments performed under magnetic stirring and with the rotating electrode $(\omega=1000 \mathrm{rpm})$, indicate that high acidity remained at the electrode surface (Table 2).

From Table 2, one can conclude that at $0.01 \mathrm{M}$ phenol concentration and relatively high $\mathrm{NaOH}$ concentration $(0.1$ and $1 \mathrm{M})$, the permeability for ferricyanide anion increases as the potential applied increases. However, at low $\mathrm{NaOH}$ concentration (0.01 and $0.05 \mathrm{M}$ ), the permeability remains almost nil even at very high applied potential. Therefore, we think that the key factor influencing the permeability of the polyphenol films is the concentration of free $\mathrm{OH}^{-}$in the solution: $\left[\mathrm{OH}^{-}\right]_{\mathrm{sol}}=[\mathrm{NaOH}]-[\mathrm{PhOH}]$;

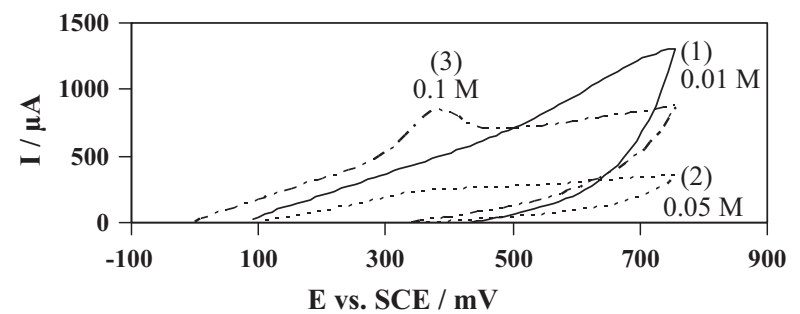

Fig. 5. Measurements of polyphenol film permeability for phenate ion. Scan rate: $100 \mathrm{mV} \mathrm{s}^{-1}$. The polyphenol films were prepared by anodic polarisation at $1800 \mathrm{mV}$ for $30 \mathrm{~min}$ at $85^{\circ} \mathrm{C}$ in $0.01 \mathrm{M}$ phenol aqueous solutions containing $0.1 \mathrm{M} \mathrm{Na}_{2} \mathrm{SO}_{4}$ and $\mathrm{NaOH}$ at $0.01 \mathrm{M}$ (curve 1), $0.05 \mathrm{M}$ (curve 2) and $0.1 \mathrm{M}$ (curve 3). 
Table 2

Relationships between the $\mathrm{NaOH}$ concentration in $0.01 \mathrm{M}$ phenol aqueous solution containing $0.1 \mathrm{M} \mathrm{Na}_{2} \mathrm{SO}_{4}$ at $85^{\circ} \mathrm{C}$ and the permeability for ferricyanide anion $P_{\text {ferr. }}^{\text {film }}$ of the polyphenol film electrosynthesized during $30 \mathrm{~min}$ on a vitreous carbon electrode at different applied potentials.

\begin{tabular}{|c|c|c|c|c|c|c|c|c|c|c|c|c|}
\hline \multirow{3}{*}{$\begin{array}{l}\text { Hydrodynamic conditions } \\
{[\mathrm{NaOH}] / \mathrm{M}} \\
E \text { vs. SCE } / \mathrm{mV}\end{array}$} & \multicolumn{8}{|c|}{ Fixed electrode and without magnetic stirring } & \multicolumn{4}{|c|}{$\begin{array}{l}\text { Electrode rotation rate of } 1000 \mathrm{rpm} \\
\text { and under magnetic stirring }\end{array}$} \\
\hline & \multicolumn{4}{|l|}{1} & \multicolumn{3}{|c|}{0.1} & \multirow[b]{2}{*}{1800} & \multicolumn{2}{|l|}{0.05} & \multicolumn{2}{|c|}{0.01} \\
\hline & 400 & 500 & 600 & 700 & 700 & 1300 & 1500 & & 1800 & 2500 & 1800 & 2500 \\
\hline$P_{\text {ferr }}^{\text {film }} \times 10^{4} / \mathrm{cm} \mathrm{s}^{-1}$ & 0 & 0 & 1961 & 3349 & 0 & 0 & 9 & 925 & 5 & 5 & 3 & 3 \\
\hline
\end{tabular}
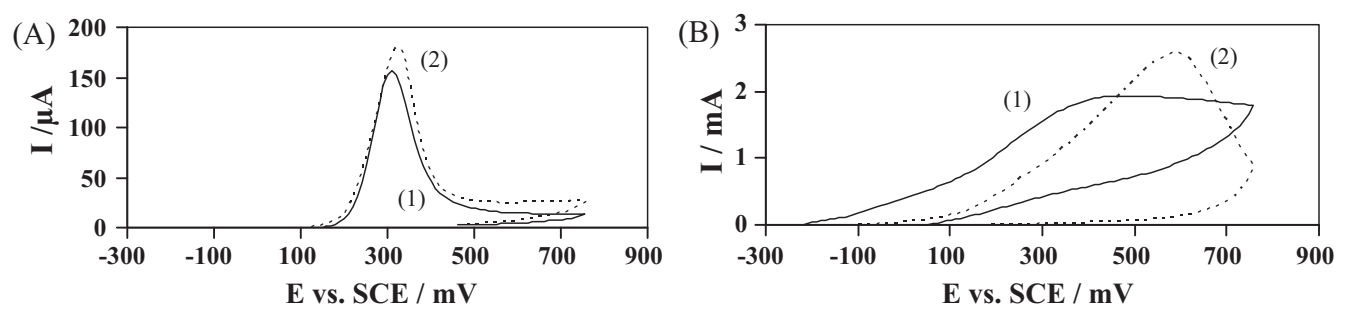

Fig. 6. Cyclic voltammograms (first cycles) of $0.05 \mathrm{M}$ phenol solution containing $0.1 \mathrm{M} \mathrm{Na}_{2} \mathrm{SO}_{4}$ and $\mathrm{NaOH}$ at $0.1 \mathrm{M}$ (curve 1 ) and $0.15 \mathrm{M}$ (curve 2 ) at $85^{\circ} \mathrm{C}$ on (A) bare $\mathrm{VC}(\mathrm{B}$ ) VC electrodes covered by polyphenol films. Scan rate: $100 \mathrm{mV} \mathrm{s}^{-1}$. Polyphenol films were electrosynthesized at $85^{\circ} \mathrm{C}$ on a rotated disk (1000 rpm) VC electrode at an applied potential of $1800 \mathrm{mV}$ in a magnetically stirred $0.05 \mathrm{M}$ phenol solution containing $0.1 \mathrm{M} \mathrm{Na}_{2} \mathrm{SO}_{4}$ and $\mathrm{NaOH}$ at $0.1 \mathrm{M}$ (curve 1 ) and $0.15 \mathrm{M}$ (curve 2 ).

the present results show that the concentration of free $\mathrm{OH}^{-}$ should be preferably higher than $0.1 \mathrm{M}$ to prepare polyphenol films with noteworthy permeability values to ferricyanide anion. Indeed, polyphenol film prepared by anodic polarisation at $1800 \mathrm{mV}$ for $30 \mathrm{~min}$ in $0.05 \mathrm{M}$ phenol solution containing $0.1 \mathrm{M}$ $\mathrm{NaOH}\left(\left[\mathrm{OH}^{-}\right]_{\text {sol }}=0.05 \mathrm{M}\right)$ and $0.1 \mathrm{M} \mathrm{Na}_{2} \mathrm{SO}_{4}$ at $85^{\circ} \mathrm{C}$ was not at all permeable for ferricyanide anion whereas the one prepared in the same conditions except that $\mathrm{NaOH}$ concentration was $0.15 \mathrm{M}$ $\left(\left[\mathrm{OH}^{-}\right]_{\text {sol. }}=0.1 \mathrm{M}\right)$ had a permeability equal to $149 \times 10^{-4} \mathrm{~cm} \mathrm{~s}^{-1}$. Fig. 6(A and B) shows cyclic voltammograms (first cycles) recorded at $85^{\circ} \mathrm{C}$ respectively on bare and polyphenol film-coated VC electrodes in $0.05 \mathrm{M}$ phenol solution containing $0.1 \mathrm{M} \mathrm{Na}_{2} \mathrm{SO}_{4}$ and $0.1 \mathrm{M}$ $\mathrm{NaOH}$ (curve 1) or $0.15 \mathrm{M} \mathrm{NaOH}$ (curve 2). Curve 1 in Fig. 6(B) exhibits a weakly defined peak for phenol oxidation indicating a very low permeability of the corresponding polyphenol film to phenate anion. A large, but better defined peak was observed for $0.15 \mathrm{M} \mathrm{NaOH}$ (curve 2 in Fig. 6 (B)) indicating that under these conditions the oxidation process occurred without inhibition and that the polyphenol film was highly permeable to phenate anion. It should be emphasized that the phenol oxidation peak on polyphenol filmcoated electrodes (Fig. 6(B)) is moved toward higher potential values as compared to that on bare VC electrode (Fig. 6(A)).

These results have shown that the removal of phenol by electropolymerisation is possible by applying a higher potential as the $\mathrm{NaOH}$ concentration decreases.

\subsubsection{Influence of phenol concentration}

The effect of phenol concentration on the permeability of polyphenol films prepared at $85^{\circ} \mathrm{C}$ on a VC rotating disk $(\omega=1000 \mathrm{rpm})$ was studied by potentiostatic polarisation at $1800 \mathrm{mV}$ during $30 \mathrm{~min}$ in magnetically stirred $0.01,0.03$ and $0.05 \mathrm{M}$ phenol aqueous solutions containing $0.1 \mathrm{M} \mathrm{NaOH}$ and $0.1 \mathrm{M}$ $\mathrm{Na}_{2} \mathrm{SO}_{4}$. Potentiostatic $I-t$ curves (not shown) reveals that the limiting current at the stationary state fell dramatically when phenol concentration increased from 0.01 to $0.03 \mathrm{M}$. Cyclic voltammograms (not shown) recorded on polyphenol film-coated VC electrodes in the same solutions show that no phenol oxidation peak was observed for $0.03 \mathrm{M}$ and $0.05 \mathrm{M}$ phenol concentrations; the electrochemical response of phenol is expressed as a wave what prevents to calculate the relative permeability for phenate anion (almost impermeable); for $0.01 \mathrm{M}$ phenol concentration, the relative permeability is equal to $143 \%$. These results as well as those presented in Section 3.2.2 for films respectively prepared in $\mathrm{NaOH}$ $0.1 \mathrm{M}$ and $0.15 \mathrm{M}$ may be explained in term of a decrease in the concentration of free $\mathrm{OH}^{-}$as the concentration of phenol in the solution rises. In particular, the decrease of the ability of the solution to oppose changes in $\mathrm{pH}$ when protons are formed on the electrode surface during water discharge can explain the origin of the permeability fall [21] (see Section 3.3.1).

\subsubsection{Influence of electrolysis time}

Polyphenol films were synthesized on a rotating ( $\omega=1000 \mathrm{rpm})$ VC electrode by anodic polarisation at $1800 \mathrm{mV}$ for various electropolymerisation times (30-120 min) in a magnetically stirred $0.01 \mathrm{M}$ phenol solution containing $0.1 \mathrm{M} \mathrm{NaOH}$ and $0.1 \mathrm{M} \mathrm{Na}_{2} \mathrm{SO}_{4}$ at $85^{\circ} \mathrm{C}$. Results presented in Table 3 reveal that the permeability decreased substantially with increasing the electropolymerisation time; similar results were obtained by Wang et al. [12]. This behaviour is interpreted in term of an increase in polyphenol film thickness with increasing electropolymerisation time; the polyphenol film thickness varies between 10 and $100 \mathrm{~nm}$ depending on the electropolymerisation conditions [25]. Fig. 7(A) shows that cyclic voltammograms of the ferricyanide anion are characterized by irreversible waves for 60 and 120 min electrosynthesis times while much more reversible peaks were observed for only $30 \mathrm{~min}$. Values of the relative permeability for phenate anion, calculated from curves (2) and (3) in Fig. 7(B), were equal to $155 \%$ and $142 \%$ respectively for 60 and 120 min indicating that the polyphenol film permeability for phenate anion is independent of electrosynthesis times. Electropolymerisation can thus occur on pre-existing polymer layer obtained by electrolysis of phenol $0.01 \mathrm{M}$ in alkaline $(0.1 \mathrm{M} \mathrm{NaOH})$ solution. This technique could be used as a way to remove phenol since under these conditions electropolymerisation proceeds as long as a current is applied to the electrode.

Table 3

Relationships between the electropolymerisation time in magnetically stirred $0.01 \mathrm{M}$ phenol aqueous solution containing $0.1 \mathrm{M} \mathrm{NaOH}$ and $0.1 \mathrm{M} \mathrm{Na}_{2} \mathrm{SO}_{4}$ at $85^{\circ} \mathrm{C}$ and the permeability $P_{\text {ferr. }}^{\text {film }}$ of the resulting polyphenol film for ferricyanide anion.

\begin{tabular}{llll}
\hline Electrosynthesis time $/$ min & 30 & 60 & 120 \\
\hline$P_{\text {ferr. }}^{\text {film }} \times 10^{4} / \mathrm{cm} \mathrm{s}^{-1}$ & 1720 & 1274 & 538 \\
\hline
\end{tabular}



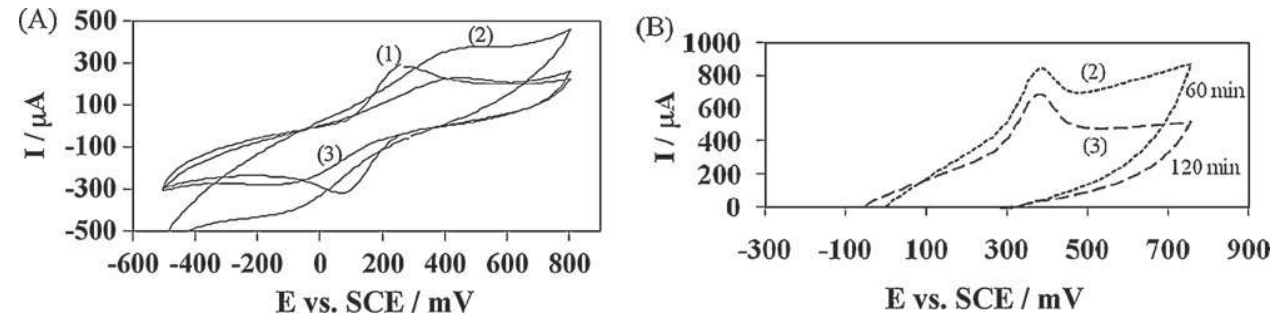

Fig. 7. Measurements of polyphenol film permeability for (A) ferricyanide and (B) phenate ions. Scan rate: (A) $500 \mathrm{mV} \mathrm{s}^{-1}$ and (B) $100 \mathrm{mV} \mathrm{s}^{-1}$. The polyphenol films were prepared by anodic polarisation on a rotating $(\omega=1000 \mathrm{rpm})$ VC electrode at $1800 \mathrm{mV}$ for various electrolysis times in $0.01 \mathrm{M}$ phenol aqueous solution containing $0.1 \mathrm{M} \mathrm{NaOH}$ and $0.1 \mathrm{M} \mathrm{Na}_{2} \mathrm{SO}_{4}$ at $85^{\circ} \mathrm{C}$. Electrolysis time: $30 \mathrm{~min}$ (curve 1); $60 \mathrm{~min}$ (curve 2) and $120 \mathrm{~min}$ (curve 3).

\subsection{Polyphenol films prepared by galvanostatic oxidation}

In practice, a treatment of phenolic compounds based on electropolymerisation should be conducted galvanostatically; as a consequence an increase of the potential is expected during the electropolymerisation. Therefore, the applied current must be determined by taking into account the transport properties of the polymeric film.

\subsubsection{Influence of applied current}

Fig. 8(A) exhibits galvanostatic $E-t$ curves recorded during polyphenol films electrosynthesis on a rotating $(\omega=1000 \mathrm{rpm}) \mathrm{VC}$ electrode at various applied currents in a magnetically stirred $0.05 \mathrm{M}$ phenol aqueous solution containing $0.15 \mathrm{M} \mathrm{NaOH}$ and $0.1 \mathrm{M}$ $\mathrm{Na}_{2} \mathrm{SO}_{4}$ at $85^{\circ} \mathrm{C}$; different electrosynthesis times were chosen in such a way that the same electric charge $(Q=3600 \mathrm{mC})$ was passed in order to prepare polyphenol films having more or less the same thickness. Galvanostatic $E-t$ curves presented in Fig. 8(A) show that the electrode potential remained constant at around $1300 \mathrm{mV}$ during the first stage of the polyphenol film electrosynthesis. The length of this step decreased when applied current increased; then the potential rose rapidly until it reached a plateau at around $2000 \mathrm{mV}$. Table 4 shows that the permeability of the film for ferricyanide anion drops from $107 \times 10^{-4} \mathrm{~cm} \mathrm{~s}^{-1}$ to $2 \times 10^{-4} \mathrm{~cm} \mathrm{~s}^{-1}$ by increasing from 1 to $3 \mathrm{~mA}$ the current applied during the film electrosynthesis. This current dependency of the permeability is in agreement with cyclic voltammograms of ferricyanide anion recorded on polyphenol film-coated VC electrodes depicted in Fig. 8(B) in that the reduction peak current decreased as the current applied increased in the range $1-3 \mathrm{~mA}$. Fig. $8(C$ and $D)$ shows cyclic voltammograms of $0.05 \mathrm{M}$ phenol aqueous solution containing $0.15 \mathrm{M} \mathrm{NaOH}$ and $0.1 \mathrm{M} \mathrm{Na}_{2} \mathrm{SO}_{4}$ recorded at $85^{\circ} \mathrm{C}$ on polyphenol film-coated VC electrodes. Cyclic voltammograms in Fig. 8(D) show that the phenol oxidation peak recorded on polyphenol film-coated electrodes is larger to that on bare electrode and displaced to more positive potentials (curve 2 in Fig. 6(A)).

Table 4 shows that when the applied current increases one observes a decrease of the permeability of the film toward the ferricyanide anion while the relative permeability of the same film with regard to the phenol increases. The current intensity effect on the polyphenol film permeability can be explained by the discharge of

\section{Table 4}

Relationships between the current $I$ applied during the electrosynthesis of a polyphenol film deposited on a rotating $(\omega=1000 \mathrm{rpm})$ vitreous carbon electrode in a magnetically stirred $0.05 \mathrm{M}$ phenol aqueous solution containing $0.15 \mathrm{M} \mathrm{NaOH}$

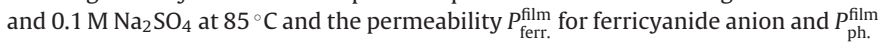
for phenol.

\begin{tabular}{lrrrr}
\hline$I / \mathrm{mA}$ & 1 & 1.5 & \multicolumn{1}{c}{2} & \multicolumn{1}{c}{3} \\
\hline Electrosynthesis time/min & 60 & 40 & 30 & 20 \\
$P_{\text {ferr. }}^{\text {film }} \times 10^{4} / \mathrm{cm} \mathrm{s}^{-1}$ & 107 & 45 & 29 & 2 \\
$P_{\text {ph. }}^{\text {film }} \%$ & 176 & 233 & 399 & 1115 \\
\hline
\end{tabular}

water which is source of protons. The current $I$ applied during films electrosynthesis can be expressed as follows:

$I=I_{\mathrm{Ph} .}+I_{\mathrm{H}_{2} \mathrm{O}}$

where $I_{\mathrm{Ph}}$ and $I_{\mathrm{H}_{2} \mathrm{O}}$ are the partial currents for respectively phenol and water electro-oxidation. $I_{\mathrm{Ph}}$. can be evaluated by the following equation: $I_{\mathrm{Ph} .}=n F A k_{\mathrm{Ph}}[\mathrm{Ph}]_{\text {sol. }}$ considering that the concentration of phenol at the electrode surface was equal to zero because the applied current $I$ was much higher than the limiting current of phenol oxidation. Indeed, for the example of Fig. 8, the limiting current of phenol oxidation (during electrosynthesis of the films) was equal to around $0.35 \mathrm{~mA}$ for $n=1, A=0.0707 \mathrm{~cm}^{2}, k_{\mathrm{Ph} .}=10^{-5} \mathrm{~m} \mathrm{~s}^{-1}$ and $[\mathrm{Ph} .]_{\text {sol. }}=0.05 \mathrm{M}$. Thus, as I increased (from 1 to $3 \mathrm{~mA}$ ), the partial current of water discharge $I_{\mathrm{H}_{2} \mathrm{O}}$ rose, producing an increase in oxygen evolution and the output of protons. The concentration of protons $\left[\mathrm{H}^{+}\right]_{\text {ele. }}$ at the electrode surface can be correlated to $I_{\mathrm{H}_{2} \mathrm{O}}$ by: $I_{\mathrm{H}_{2} \mathrm{O}}=n F A k_{\mathrm{H}^{+}}\left[\mathrm{H}^{-}\right]_{\text {ele. }}$ considering that the bulk concentration of protons $\left[\mathrm{H}^{+}\right]_{\mathrm{sol}}$ was equal to zero due to hydrodynamic conditions (electrode rotation, $\omega=1000 \mathrm{rpm}$ plus magnetic stirring) and the relatively high concentration of free hydroxide ion in the solution $\left(\left[\mathrm{OH}^{-}\right]_{\text {sol }}=0.1 \mathrm{M}\right)$. Thus, concentrations $\left[\mathrm{H}^{+}\right]_{\text {ele }}$, calculated for $n=1$ and $k_{\mathrm{H}^{+}}=10^{-5} \mathrm{~m} \mathrm{~s}^{-1}$, were equal to around $0.1 \mathrm{M}$ and $0.4 \mathrm{M}$ respectively for $I$ equal to 1 or $3 \mathrm{~mA}$. These results show that for $I=3 \mathrm{~mA}$, the concentration of protons at the electrode surface $\left(\left[\mathrm{H}^{+}\right]_{\text {ele }}=0.4 \mathrm{M}\right)$ was four times higher than that of free hydroxide ion in the solution $\left(\left[\mathrm{OH}-\mathrm{H}^{+}\right]_{\text {sol. }}=0.1 \mathrm{M}\right)$. As a result, the electrode/solution interface remained acid though electrosynthesis of the polyphenol film was performed with an electrode rotation rate of $1000 \mathrm{rpm}$ and under magnetic stirring. If we assume that polyphenol films prepared here had the same thickness, the drop of permeability for ferricyanide anion (Table 4) can be explained by a stronger acidity at the electrode surface during polyphenol film electrosynthesis as I increased.

The contradictory between the increase in the apparent permeability for phenol (\%) $P_{\mathrm{Ph} \text {. }}^{\text {film }}$ and the dramatic decrease of the permeability for ferricyanide anion $P_{\text {ferr. }}^{\text {film }}$ when the applied current increases (Table 4) can be interpreted in term of a change in the microstructure of the polyphenol film. We think that increasing the applied current and therefore the concomitant oxygen evolution increases the density of small pores (permeable for phenate and not for ferricyanide anion) to the detriment of that of large ones (permeable for both phenate and ferricyanide anions). According to Rothwell et al.'s suggestion [18] we intend to study these films by scanning electron microscopy to understand these effects.

For the removal of phenol by electropolymerisation the operating conditions should favour a high permeability of the film for phenate anion. Comparison between values of $P_{\text {ferr. }}^{\text {film }}$ (Table 4 ) and $P_{\text {ferr. }}^{\text {sol. }}\left(P_{\text {ferr. }}^{\text {sol. }}=45 \times 10^{-4} \mathrm{~cm} \mathrm{~s}^{-1}\right.$ for $\omega=1000 \mathrm{rpm}$; Fig. 4 ) shows that the rate of ferricyanide reduction was limited by the membrane permeability for polyphenol films prepared at currents higher than $2 \mathrm{~mA}$ whereas it was under solution transport control for currents lower than $1.5 \mathrm{~mA}$. The above results show that electrolysis 

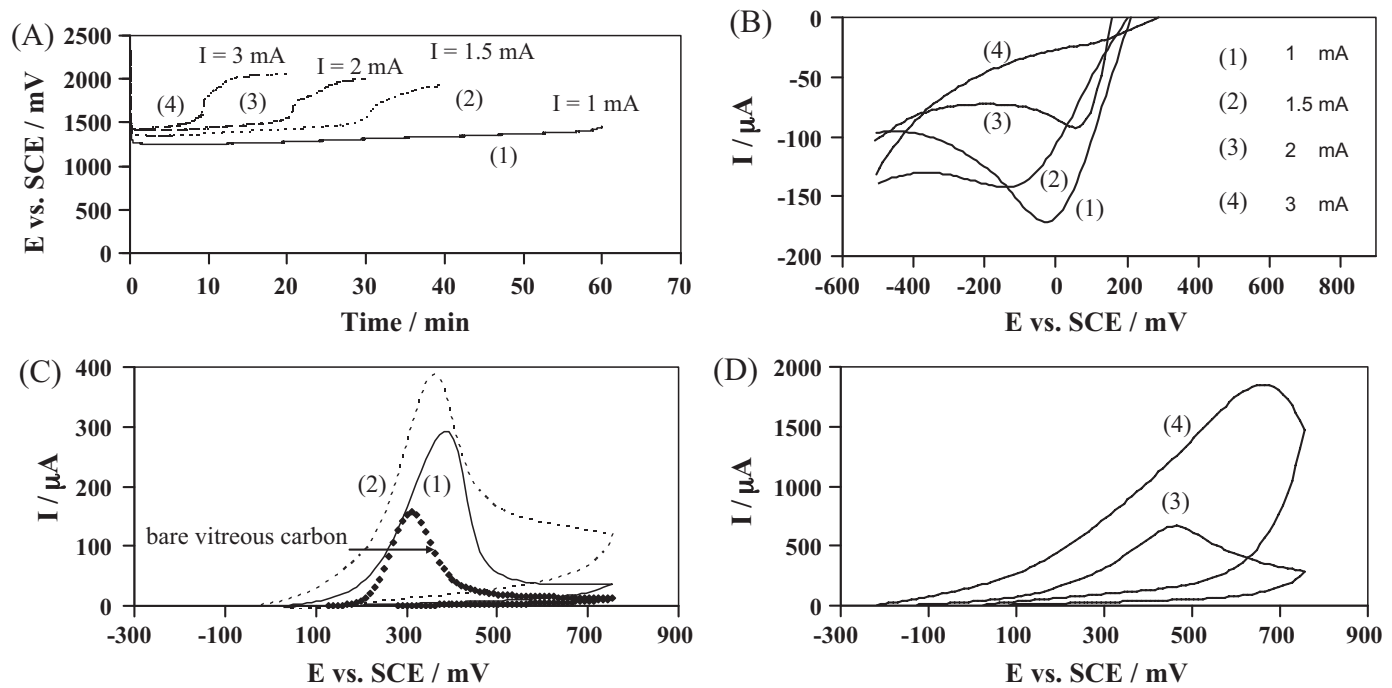

Fig. 8. (A) Galvanostatic $E-t$ curves recorded during polyphenol films electrosynthesis on a rotating ( $\omega=1000$ rpm) VC electrode at various applied currents in a magnetically stirred $0.05 \mathrm{M}$ phenol aqueous solution containing $0.15 \mathrm{M} \mathrm{NaOH}$ and $0.1 \mathrm{M} \mathrm{Na}_{2} \mathrm{SO}_{4}$ at $85^{\circ} \mathrm{C}$. Applied current: (1) $1 \mathrm{~mA}$ for $60 \mathrm{~min}$, (2) $1.5 \mathrm{~mA}$ for $40 \mathrm{~min}$, (3) $2 \mathrm{~mA}$ for $30 \mathrm{~min}$ and (4) $3 \mathrm{~mA}$ for $20 \mathrm{~min}$. (B-D) Measurements of polyphenol film permeability for (B) ferricyanide and (C and D) phenate ions. Scan rate: (B) $500 \mathrm{mV} \mathrm{s}^{-1}$ and (C and D) $100 \mathrm{mV} \mathrm{s}^{-1}$.

performed at an applied current slightly higher than the limiting current of phenol oxidation should allow the removal of phenol.

\subsubsection{Influence of electrode rotation and magnetic stirring}

Galvanostatic $E-t$ curves were recorded at $85^{\circ} \mathrm{C}$ on a VC electrode at an applied current of $2 \mathrm{~mA}$ in $0.05 \mathrm{M}$ phenol aqueous solution containing $0.15 \mathrm{M} \mathrm{NaOH}$ and $0.1 \mathrm{M} \mathrm{Na}_{2} \mathrm{SO}_{4}$; curves were registered either in a quiescent solution or for an electrode rotation rate of $1000 \mathrm{rpm}$ and a magnetic stirring. The $E-t$ curves have the same shape except that the potential plateau at $2000 \mathrm{mV}$ was reached right from the beginning in the case of polyphenol film electrosynthesized in a quiet solution. The permeability for ferricyanide anion dropped from $29 \times 10^{-4} \mathrm{~cm} \mathrm{~s}^{-1}$ (Table 4) for polyphenol film electrosynthesized on a rotating electrode and under magnetic stirring to zero in the case of a fixed electrode and unstirred phenol solution. As in Section 3.2.1, these results may be interpreted assuming an accumulation of high concentration of protons $\mathrm{H}^{+}$at the electrode surface which blocks the permeability of the polyphenol film electrosynthesized on a fixed electrode in unstirred solution [21].

\section{Conclusions}

This work demonstrates that the permeability of polyphenol films deposited by electrochemical polymerisation on a vitreous carbon electrode depends strongly on the composition of the starting phenol solution, temperature, applied potential or current, electrosynthesis time and hydrodynamic conditions. We have shown that the concentration of free $\mathrm{OH}^{-}$in the starting phenol solution $\left(\left[\mathrm{OH}^{-}\right]_{\text {sol. }}=[\mathrm{NaOH}]-[\mathrm{PhOH}]\right)$ must be higher than around $0.1 \mathrm{M}$ to prepare polyphenol films permeable to both ferricyanide and phenate anions; this was verified by varying $\mathrm{NaOH}$ concentration for the same concentration of phenol and vice versa; the relatively high free $\mathrm{OH}^{-}$concentration was necessary to instantaneously neutralize the acidity, at the electrode surface, arising from the concomitant oxygen evolution occurring during the polyphenol film electrosynthesis. Electrochemical polymerisation conducted at high temperature $\left(85^{\circ} \mathrm{C}\right)$ yields high permeable polyphenol films at low applied potentials. Nevertheless, polyphenol films that have suitable permeability were synthesized at low temperature but at high applied potential. For the removal of phenol from wastewater by electropolymerisation, it would be better to use high temperature and low potential in order to minimize the parasitic reaction of oxygen evolution which affects the current yield. We have also shown that polyphenol films prepared at $1800 \mathrm{mV}$ from $0.01 \mathrm{M}$ phenol and $0.1 \mathrm{M} \mathrm{NaOH}$ have low permeability, especially when electrolysis time increases; this was interpreted in term of an increase in the polyphenol film thickness. The apparent permeability of polyphenol films prepared galvanostatically from $0.05 \mathrm{M}$ phenol and $0.15 \mathrm{M} \mathrm{NaOH}$ at $85^{\circ} \mathrm{C}$ increased for phenate anion as the applied current increased. These results could be interpreted in terms of (1) the increase in the local acidity at the electrode surface and (2) an increase in the density of small pores (permeable for phenate and not for ferricyanide anion) to the detriment of large pores (permeable for both phenate and ferricyanide anions) with increasing the concomitant oxygen evolution. It was shown that polyphenol films prepared on a rotating electrode and a stirred solution were more permeable than those synthesized on a fixed electrode and an unstirred solution.

\section{References}

[1] N. Belhadj Tahar, A. Savall, Electrochimica Acta 54 (2009) 4809.

[2] M. Gattrell, B. MacDougall, Journal of the Electrochemical Society 146 (1999) 3335.

[3] H. Kuramitz, M. Matsushita, S. Tanaka, Water Research 38 (2004) 2331.

[4] N. Belhadj Tahar, R. Abdelhedi, A. Savall, Journal of Applied Electrochemistry 39 (2009) 663.

[5] Y. Zhang, Q. Li, H. Cui, J. Zhai, Electrochimica Acta 55 (2010) 7219.

[6] X-Y. Li, Y-H. Cui, Y-J. Feng, Z-M. Xie, J-D. Gu, Water Research 39 (2005) 1972.

[7] J. Wang, M. Jiang, F. Lu, Journal of Electroanalytical Chemistry 444 (1998) 127.

[8] P.I. Iotov, S.V. Kalcheva, Journal of Electroanalytical Chemistry 442 (1998) 19.

[9] J-L. Boudenne, O. Cerclier, P. Bianco, Journal of the Electrochemical Society 145 (1998) 2763.

10] G. Mengoli, M.M. Musiani, Electrochimica Acta 31 (1986) 201.

[11] Ch. Comninellis, C. Pulgarin, Journal of Applied Electrochemistry 21 (1991) 703.

[12] J. Wang, S-P. Chen, M.S. Lin, Journal of Electroanalytical Chemistry 273 (1989) 231.

[13] R.L. McCarley, Journal of Electrochemical Society 137 (1990) 218C.

[14] I. Losito, F. Palmisano, P.G. Zambonin, Analytical Chemistry 75 (2003) 4988.

[15] R.L. McCarley, E.A. Irene, R.W. Murray, Journal of Physical Chemistry 95 (1991) 2492.

[16] A. Witkowski, M.S. Freund, A. Brajter-Toth, Analytical Chemistry 63 (1991) 622

[17] M.D. Imisides, R. John, P.J. Riley, G.G. Wallace, Electroanalysis 3 (1991) 879.

[18] S.A. Rothwell, C.P. McMahon, R.D. O'Neeill, Electrochimica Acta 55 (2010) 1051 
[19] P. Gros, T. Gibson, A. Bergel, M. Comtat, Journal of Electroanalytical Chemistry 437 (1997) 125

[20] N. Belhadj Tahar, A. Savall, Electrochimica Acta 55 (2009) 465.

[21] N. Belhadj Tahar, A. Savall, Journal of Applied Electrochemistry 41 (2011) 983.

[22] V.G. Levich, Physicochemical Hydrodynamics, Prentice-Hall, Englewood Cliffs, NJ, 1962.
[23] J. Cruz, M. Kawasaki, W. Gorski, Analytical Chemistry 72 (2000) 680

[24] C.A. Martinez-Huitle, C. Carlesi Jara, M. Cerro-Lopez, M.A. Quiroz, Canadian Journal of Analytical Sciences and Spectroscopy 54 (2009) 53.

[25] R. Lapuente, F. Cases, P. Garcés, E. Morallon, J.L. Vasquez, Journal of Electroanalytical Chemistry 451 (1998) 163. 